\title{
THE RELATION BETWEEN PHOTOCONDUCTIVITY THRESHOLD AND OPEN-CIRCUIT VOLTAGE IN ORGANIC SOLAR CELLS
}

\author{
R. Grzibovskis ${ }^{1 *}$, A. Ruduss², A. Polaks ${ }^{1}$ \\ ${ }^{1}$ Institute of Solid State Physics, University of Latvia, \\ 8 Kengaraga Str., Riga, LV-1063, LATVIA \\ ${ }^{2}$ Faculty of Materials Science and Applied Chemistry, \\ Riga Technical University, \\ 3/7 P. Valdena Str., Riga, LV-1048, LATVIA \\ *E-mail: raitis.g@cfi.lu.Iv
}

Most of the solar cell parameters (short-circuit current, fill factor, power conversion efficiency) can only be determined by creating and measuring the solar cell. However, there is an empirical relation that links energy level values of the materials in the active layer to an opencircuit voltage $\left(\mathrm{U}_{\text {oc }}\right)$ of the solar cell. Due to a variety of possible methods used to determine energy level values and the dispersion of obtained results, this estimate is not always correct. Even if correct energy level values are obtained for separate materials, energy level shift takes place at the interfaces when two materials are mixed. That is why a simple and reliable experimental method for $U_{o c}$ estimation is required. Usually, photoconductivity is used to obtain the energy gap between molecule ionization energy and electron affinity of a single material. When two materials are mixed, direct charge transfer from donor to acceptor molecule can be observed. The threshold energy $\left(\mathrm{E}_{\mathrm{CT}}\right)$ shows the real difference between donor molecule ionization energy and acceptor molecule electron affinity. This difference should correspond to the $\mathrm{U}_{\mathrm{oc}}$. The present study makes the comparison between the open-circuit voltage estimated from material energy level values, the obtained $\mathrm{E}_{\mathrm{CT}}$ values for various donor:acceptor systems, and the real $\mathrm{U}_{\mathrm{oc}}$ obtained from solar cell measurements. Strong correlation between $\mathrm{E}_{\mathrm{CT}}$ and $\mathrm{U}_{\mathrm{oc}}$ is obtained and the photoconductivity measurements can be used in the estimation of $\mathrm{U}_{\mathrm{oc}}$.

Keywords: Energy levels, direct charge transfer, open-circuit voltage, organic materials, organic solar cells, photoconductivity. 
Environmental concerns compel many nations to develop technologies that allow collecting renewable energy and decreasing the use of fossil fuels. Solar cells allow directly turning the sunlight into electricity. The wide variety of organic materials combined with the possibility to vary their molecule structure makes them an attractive field of research. The efficiency of organic solar cells is steadily increasing and nowadays reaches $18 \%$ [1]. Solar cells are characterised by several parameters, such as short-circuit current $\left(\mathrm{I}_{\mathrm{sc}}\right)$, open-circuit voltage $\left(\mathrm{U}_{\mathrm{oc}}\right)$, fill factor $(\mathrm{FF})$, and power conversion efficiency (PCE) [2], [3]. All previously mentioned parameters are affected not only by the properties of each separate material but also by material compatibility. $I_{\text {sc }}$ depends on two factors: the efficiency of charge carrier generation in the active layer, and the efficiency of charge carrier extraction from the solar cell. $U_{o c}$ is mainly defined by the energy levels of the materials used in the active layer. The prediction of open-circuit voltage is based on the empirical relation that consists of donor and acceptor molecule energy levels:

$U_{o c}=1 / e\left(I_{d}-E_{a, a}\right)-0.3 V$,

where $e$ is the elementary charge, $I_{d}$ is the molecule ionization energy of the electron donor material, and $E_{a, a}$ is the electron affinity of the electron acceptor material [4]. Equation (1) is simple and would potentially allow us to estimate the most promising donor:acceptor combination without the need of time- and resource-consuming solar cell manufacturing. That is why the correct determination of energy level values is crucial. The most common method for molecule ionization energy determination is ultraviolet photoelectron spectroscopy (UPS) [5], [6].
Photoelectron yield spectroscopy (PYS) is used as an alternative method [7]-[10] as it is simple and does not require an ultrahigh vacuum. Although the principle of these methods is similar, reported results can differ from author to author. For example, ionization energy values for popular electron donor polymer poly(3-hexylthiophene-2,5-diyl) $(\mathrm{P} 3 \mathrm{HT})$ in various scientific papers ranges from 4.7 to $5.3 \mathrm{eV}$ [11]-[15]. In our previous studies, we obtained the value of 4.54 $\pm 0.03 \mathrm{eV}$ [9], [10]. Correct estimation of electron affinity is even more complicated. Although it can be directly determined using inverse photoemission spectroscopy (IPES) [16], [17], due to the poor energy resolution and complexity of the method, IPES is rarely used. Usually, the electron affinity value is obtained indirectly from molecule ionization energy and energy gap measurements. The energy gap between molecule ionization energy and electron affinity can be estimated either from absorption edge or from photoconductivity measurements [18]. A relatively popular method for the energy level estimation of organic semiconductors in solution is cyclic voltammetry. Yet there is still debate about the validity and precision of this method [19], [20].

Additionally, it has been shown that the energy level shift takes place at the organic material interface [10], [21], [22]. It means that even if the correct energy level values for each separate material are obtained, the real gap between donor molecule ionization energy and acceptor material electron affinity can differ from the estimated value when materials are mixed. In that case, the predicted $U_{\text {oc }}$ value may differ from the real value. That is why a simple, reliable, and direct method is needed for the correct prediction of $U_{o c}$. 
In the photogeneration process, the donor molecule is excited by the absorption of a photon. In the next step, the electron is transferred to the acceptor molecule [3]. It is also possible to transfer electron directly from the donor molecule to the acceptor molecule without the excitation of the donor molecule. This process is called direct charge transfer (CT). The energy of this transition shows the real energy gap between the ionization energy of donor material and the electron affinity of acceptor material at the interface. While this energy could be determined optically by measuring the absorption or luminescence spectra [23], [24], it is a complicated task due to the low probability of CT transition. In these measurements, the signal is small and is close to the sensitivity threshold of the equipment. Alternatively, CT transition can be observed in photoconductivity measurements [25]. Usually, photoconductivity measurements are used to obtain the energy gap between the ionization energy and electron affinity of a single material. When two materials are mixed creating bulk heterojunction, the photoconductivity threshold shows the lowest energy required to transfer an electron from the donor molecule to the acceptor molecule. This could allow us to evaluate the real gap between energy levels in the system and to predict the maximum obtainable voltage of solar cells more precisely. This study aims to show the relation between CT energy obtained from photoconductivity measurements, prediction of $\mathrm{U}_{\text {oc }}$ based on the measured energy levels of studied materials, and the real open-circuit voltage of created solar cells. Photoconductivity measurements are done for various donor:acceptor mixtures. The obtained threshold values are compared to the $\mathrm{U}_{\mathrm{oc}}$ obtained from solar cells using the same donor:acceptor combinations.

\section{EXPERIMENTAL}

\subsection{Studied Materials}

In this study, commercially available organic materials, as well as original materials synthesized at Riga Technical University are studied. The chosen materials are either well-known compounds used in the efficient solar cells (P3HT, PCBM, PBDBT, Y5, PCDTBT, PCPDTBT) or promising original compounds created in previous

\section{Sample Preparation}

Three series of samples were made:

1. samples for energy level determination;

2. samples for CT measurements;

3. photovoltaic cells for $\mathrm{U}_{\text {oc }}$ determination.

Samples for energy determination were made on etched ITO covered glass (Präzi- studies (DC-1, DC-2, DZC-3). Molecule structures are shown in Fig. 1. Commercially available materials are obtained from Sigma-Aldrich. The synthesis of DC-1 and DC-2 has previously been described in [26], while the synthesis of DZC-3 has been described in [27].

sions Glas and Optik GmbH). Solutions in chloroform with the concentration of 15-20 $\mathrm{mg} / \mathrm{ml}$ were prepared and spin-coated at the speed of $600 \mathrm{rpm}$, acceleration of 600 $\mathrm{rpm} / \mathrm{s}$, and spinning time of $40 \mathrm{~s}$. Afterward, the samples were dried on a hotplate for 15 $\min$ at $70^{\circ} \mathrm{C}$. The thickness of samples was 
between 500 and $700 \mathrm{~nm}$. These samples were used in PYS measurements to obtain the ionization energy of the studied materials. After the ionization energy measurements, $30 \mathrm{~nm}$ thick semitransparent aluminum (Al) electrodes were deposited on top of the organic layer by thermal evaporation in a vacuum $\left(\sim 1 \cdot 10^{-5}\right.$ mbar $)$ using Edwards Auto 306 thermal evaporator. The obtained "sandwich" type samples (ITO/studied material/ $\mathrm{Al}$ ) were used for photoconductivity measurements.

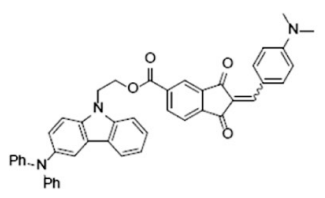

DC-1

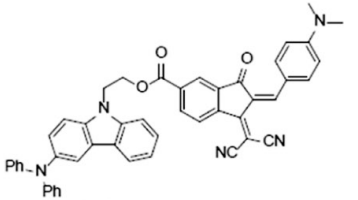

DC-2

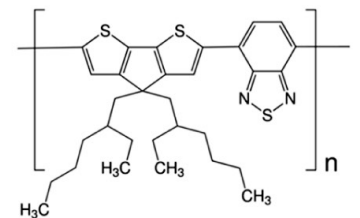

PCPDTBT

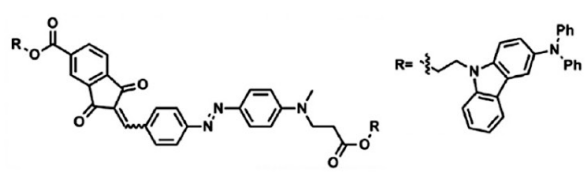

DZC-3

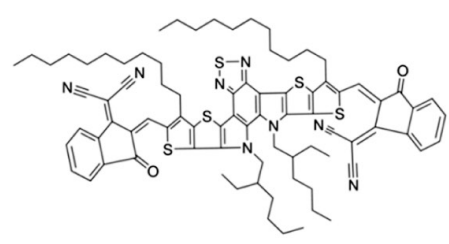

$Y 5, \geq 99 \%$

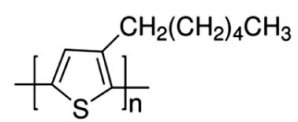

$\mathrm{P} 3 \mathrm{HT}$, regioregular

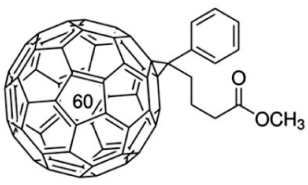

PCBM, $>99 \%$

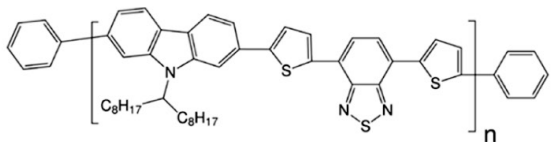

PCDTBT

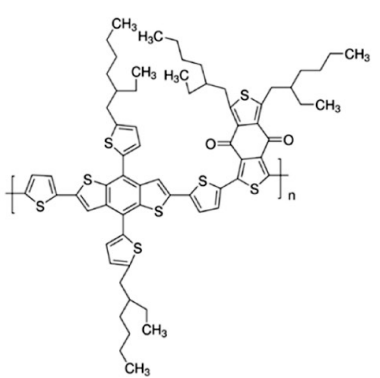

PBDB- $T$

Fig. 1. Molecule structures of studied materials.

Samples for CT measurements were from solutions where the studied materials were dissolved in chloroform with a concentration of around $15 \mathrm{mg} / \mathrm{ml}$. Then two solutions were mixed with the mass ratio of $1: 1$. The obtained mixtures were spin-coated at the speed of $600 \mathrm{rpm}$, acceleration of 600 $\mathrm{rpm} / \mathrm{s}$, and spinning time of $40 \mathrm{~s}$, obtaining bulk heterojunction thin films. Afterward, the samples were dried on a hotplate for $15 \mathrm{~min}$ at $70{ }^{\circ} \mathrm{C} .30 \mathrm{~nm} \mathrm{Al}$ electrodes were deposited on top of the film by thermal evaporation in vacuum using Edwards Auto 306 thermal evaporator. The structure of samples was ITO/ donor:acceptor/ Al.
Solar cells with the structure of ITO/ PEDOT:PSS/ donor:acceptor/ LiF/ Al were made. The layers were deposited on etched indium tin oxide (ITO) glass (Präzisions Glas and Optik GmbH). At first, PEDOT:PSS (A14083) was spin-coated at the speed of $2000 \mathrm{rpm}$, acceleration of $2000 \mathrm{rpm} / \mathrm{s}$, and spinning time of $60 \mathrm{~s}$. Afterward, the samples were dried on a hotplate for $15 \mathrm{~min}$ at $120{ }^{\circ} \mathrm{C}$. Solutions in chloroform with the concentration of 6 $\mathrm{mg} / \mathrm{ml}$ of the studied materials were used. Various donor:acceptor combinations were prepared by mixing two solutions with the mass ratio of $1: 1$. The obtained mixtures 
were spin-coated in a glovebox in an argon atmosphere. Spin-coating parameters were the following: rotation speed of $1000 \mathrm{rpm}$, acceleration of $1000 \mathrm{rpm} / \mathrm{s}$, and spinning time of $40 \mathrm{~s}$. The samples were dried on a

\subsection{Measurements}

Photoelectron emission measurements were done in a vacuum $\left(\sim 2 \cdot 10^{-5}\right.$ mbar $)$ using a self-built measurement system. ENERGETIQ Laser-Driven Light Source (LDLS EQ-99) was used as a light source. Spectral Products DK240 1/4m monochromator was used to control the energy of photons reaching the sample. The spectral range of these measurements was between 4.0 and $6.8 \mathrm{eV}$ with a step of $0.05 \mathrm{eV}$. Cylindrical lens before the quartz window of the vacuum chamber ensured irradiation area of $5 \mathrm{x}$ $10 \mathrm{~mm}$ of the sample area. A copper electrode located $2 \mathrm{~cm}$ away from the sample was used to collect the emitted electrons. Keithley 617 electrometer was used as a voltage source as well as the equipment for electric current measurements. A voltage of $50 \mathrm{~V}$ was applied between electrode and sample to improve the obtained electrical signal. Detailed experimental procedure and data processing has been previously described in [9].

The setup for photoconductivity measurements was similar to that used in photoelectron emission experiments. Here, a short focal length spherical lens was used to focus the light on around $1 \mathrm{x} 1 \mathrm{~mm}$ surface area. Thin films were irradiated through the deposited semitransparent Al electrode and the electrical current between $\mathrm{Al}$ and ITO electrodes was measured. In the case hotplate for $15 \mathrm{~min}$ at $70{ }^{\circ} \mathrm{C} .1 \mathrm{~nm} \mathrm{LiF}$ and $100 \mathrm{~nm} \mathrm{Al}$ were deposited using Moorfield Nanotechnology MiniLab LT090A-MX thermal evaporator in Jacomex glovebox. Al deposition rate was $0.3 \mathrm{~nm} / \mathrm{s}$.

of pure materials where photoconductivity was used to determine the energy gap between their molecule ionization energy and electron affinity, the spectral range depended on their absorption spectrum. In the case of mixed samples for CT measurements, the chosen region was wider starting in the infrared part of the spectrum at $2100 \mathrm{~nm}$ (0.59 eV photon energy). The generated current was measured with Keithley 617 electrometer. Photocurrent spectral dependence was measured with a step of $5 \mathrm{~nm}$. Data processing was done according to [18]. From photoconductivity measurements, the gap $\left(E_{\text {gap }}\right)$ between ionization energy and electron affinity $\left(E_{a}\right)$ was obtained for each of the studied materials. Knowing the ionization energy and the gap energy, electron affinity was calculated as follows:

$E_{a}=I-E_{g a p}$.

Photovoltaic effect measurements were done using Keithley 6517B electrometer. A solar simulator ScienceTech SS150 with a light intensity of $100 \mathrm{~mW} / \mathrm{cm}^{2}$ and a standard AM 1.5 filter was used as a light source. Current-voltage characteristics were measured with a step of $0.02 \mathrm{~V}$. Point in current-voltage characteristics where the electrical current value is closest to $0 \mathrm{~A}$ is considered $\mathrm{U}_{\mathrm{oc}}$.

\section{RESULTS AND DISCUSSION}

Although the energy level values for commercial compounds were available in the literature, the ionization energy and electron affinity were measured for all the 
studied materials. It was done to ensure that all the values were obtained using the same method in the same conditions. The values summarised in Table 1 were used to estimate the $U_{\text {oc,est }}$ value for various donor:acceptor material combinations according to Eq. (1).

Table 1. Studied Materials and Their Energy Level Values

\begin{tabular}{|l|c|c|}
\hline Material & $\mathbf{I}, \mathbf{e V} \pm \mathbf{0 . 0 3} \mathbf{e V}$ & $\mathbf{E}_{\mathbf{a}}, \mathbf{e V} \pm \mathbf{0 . 0 5} \mathbf{e V}$ \\
\hline P3HT & 4.54 & 2.79 \\
\hline PCBM & 6.08 & 3.63 \\
\hline PBDB-T & 4.87 & 3.15 \\
\hline Y5 & 5.55 & 3.87 \\
\hline PCDTBT & 5.10 & 3.40 \\
\hline PCPDTBT & 4.90 & 3.60 \\
\hline DC-1 & 5.16 & 3.36 \\
\hline DC-2 & 5.15 & 3.48 \\
\hline DZC-3 & 5.13 & 3.41 \\
\hline
\end{tabular}

For separate materials, the photoconductivity threshold defines the gap between molecule ionization energy and electron affinity. It means that by increasing the photon energy near the gap energy, the measured photocurrent rapidly increases even by several orders of magnitude. Below the $\mathrm{E}_{\text {gap }}$ there is usually no photoconductivity or small signal generated by the impurities in the film. As an example, P3HT and DZC-3 photoconductivity spectral dependence is shown in Fig. 2a. Although the $\mathrm{E}_{\text {gap }}$ for both of these materials is similar (1.75 for P3HT and 1.72 for DZC-3), it can be seen that there is a small photocurrent till around $1.4 \mathrm{eV}$ for P3HT, while no photoconductivity could be observed below $1.6 \mathrm{eV}$ for DZC-3.

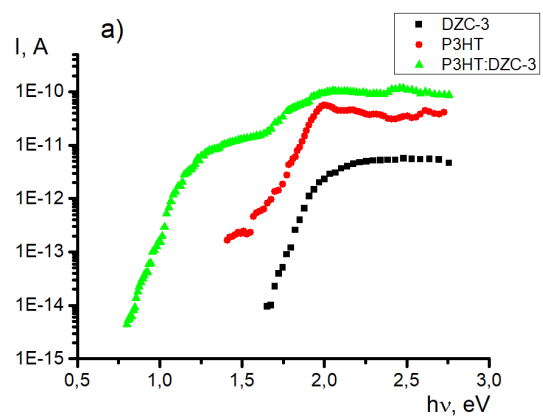

When mixed, a photoconductivity signal can be observed in the infrared spectral region starting from $0.80 \mathrm{eV}$ (see Fig. 2a). Here, the photon energy is too low to directly excite any of the studied materials and we observe direct charge transfer from P3HT to DZC-3. The probability of direct $\mathrm{CT}$ is low and the obtained signal near the threshold energy is almost 4 orders of magnitude lower than the signal of classical photoconductivity. Similar photoconductivity spectral dependence can be observed for other electron donor and acceptor combinations (see Fig. 2b). In all cases, the observed photoconductivity threshold energy for mixtures is lower than the threshold energy for separate materials.

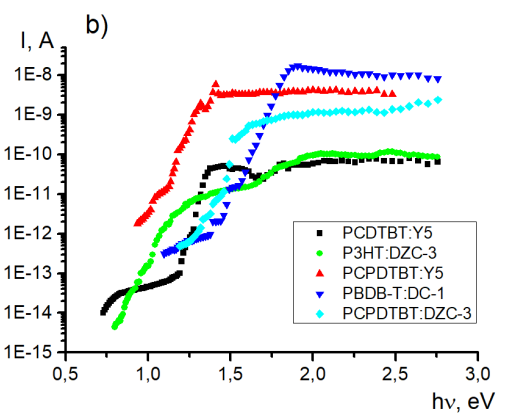

Fig. 2. Photocurrent spectral dependence for a) DZC-3, P3HT, and P3HT:DZC-3 sample; b) various donor:acceptor mixtures. 
The estimated $U_{\text {oc,est }}$ values, and CT threshold values $\left(\mathrm{E}_{\mathrm{CT}}\right)$ for various donor:acceptor combinations were compared to the real $U_{o c}$ values obtained from photovoltaic effect measurements of created solar cells. The error for $\mathrm{U}_{\text {oc,est }}$ is \pm 0.08 $\mathrm{V}$ due to the errors of energy level value determination, the error of $\mathrm{U}_{\text {oc }}$ is \pm 0.02 $\mathrm{V}$ as a measurement step, and the error of $\mathrm{E}_{\mathrm{CT}}$ is $\pm 0.03 \mathrm{eV}$. As can be seen in Fig. 3, the correlation between estimated and real open circuit voltage values is moderate. The trend is generally the same - the higher the estimated $U_{o c, e s t}$, the higher the real value. Nevertheless, the data are scattered and in several cases, there is an immense overestimation. Linear approximation of $\mathrm{U}_{\text {oc,est }}$ gives a correlation coefficient of $\mathrm{r}=0.61$, which is considered a moderate correlation.

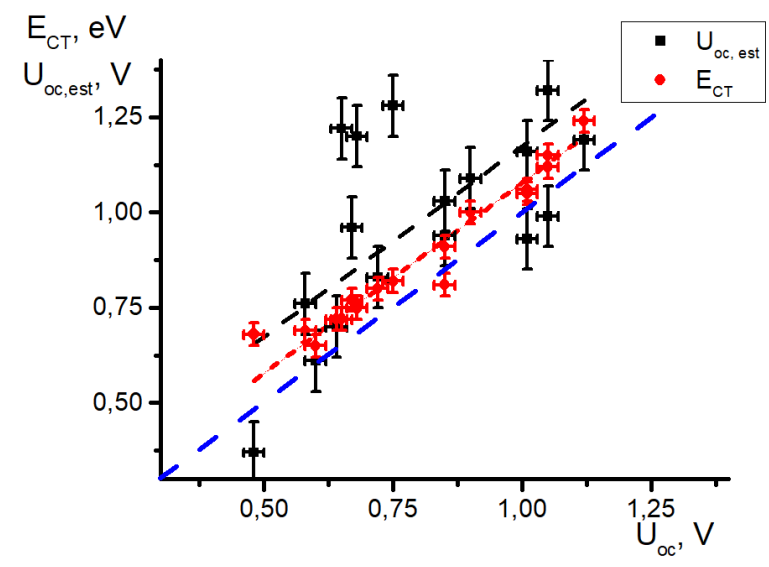

Fig. 3. The $\mathrm{E}_{\mathrm{CT}}$ and $\mathrm{U}_{\text {oc,est }}$ comparison to $\mathrm{U}_{\mathrm{oc}}$. Black dashed line is a linear approximation of $\mathrm{U}_{\text {oc,est }}$ values; red dashed line is a linear approximation of $\mathrm{E}_{\mathrm{CT}}$ values; the blue dashed line shows a perfect fit.

The photoconductivity threshold values are less scattered and are closer to the $\mathrm{U}_{\text {oc }}$ values. Linear approximation of the results gives a relation between $\mathrm{E}_{\mathrm{CT}}$ and $\mathrm{U}_{\mathrm{oc}}$ :

$U_{o c}=E_{C T}-0.08 \mathrm{~V}$.

The slight overestimation of $\mathrm{E}_{\mathrm{CT}}$, especially towards the lower $U_{\text {oc }}$ values, could be related to the sensitivity of the measure- ments. The signal-to-noise ratio and thus the precision of the measurements could be improved by a light source with higher intensity in the infrared region of the spectrum. Also, the quality of the samples can greatly influence the stability and sensitivity of the measurements. The correlation coefficient, in this case, is $r=0.96$ which shows a very strong correlation between photoconductivity threshold energy and $U_{o c}$ values.

\section{CONCLUSIONS}

We have shown that the estimation of open-circuit voltage should not be based only on energy level values obtained from bulky films of pure materials. Using rela- tively simple photoconductivity measurements, we were able to get direct CT threshold energy which corresponded to the real energy gap between molecule ionization 
energy of electron donor and electron affinity of electron acceptor material. Although this threshold value slightly overestimates the real $U_{o c}$ value, the deviations are smaller compared to the $U_{\text {ocest }}$ obtained from energy level values.

\section{ACKNOWLEDGEMENTS}

Financial support provided by Scientific Research Project for Students and Young Researchers No. SJZ/2020/08 implemented at the Institute of Solid State Physics, University of Latvia is greatly acknowledged. Institute of Solid State Physics, Univer- sity of Latvia as the Centre of Excellence has received funding from the European Union's Horizon 2020 Framework Programme H2020-WIDESPREAD-01-20162017-TeamingPhase2 under grant agreement No. 739508, project CAMART ${ }^{2}$.

\section{REFERENCES}

1. Liu, Q., Jiang, Y., Jin, K., Qin, J., Xu, J., Li, W. ... \& Ding, L. (2020). 18\% Efficiency Organic Solar Cells. Sci. Bull., 65, 272-275. doi:10.1016/j.scib.2020.01.001.

2. Qi, B., \& Wang, J. (2013). Fill Factor in Organic Solar Cells. Phys. Chem. Chem. Phys., 15, 8972-8982. doi:10.1039/ c3cp51383a.

3. Deibel, C., \& Dyakonov, V. (2010). PolymerFullerene Bulk Heterojunction Solar Cells. Reports Prog. Phys., 73. doi:10.1088/00344885/73/9/096401.

4. Scharber, M.C., Mühlbacher, D., Koppe, M., Denk, P., Waldauf, C., Heeger, A.J., \& Brabec, C.J. (2006). Design Rules for Donors in Bulk-Heterojunction solar Cells - Towards $10 \%$ Energy-Conversion Efficiency. Adv. Mater., 18, 789-794. doi:10.1002/adma.200501717.

5. Chandekar, A., \& Whitten, J.E. (2005). Ultraviolet Photoemission and Electron Loss Spectroscopy of Oligothiophene Films. Synth. Met., 150, 259-264. doi:10.1016/j. synthmet.2005.02.013.

6. Casu, M.B., Imperia, P., Schrader, S., \& Falk, B. (2001). Ultraviolet Photoelectron Spectroscopy of Thin Films of New Materials for Multilayer Organic Light Emitting Diodes. Surf. Sci., 482-485, 12051209. doi:10.1016/S0039-6028(01)00733-6.
7. Honda, M., Kanai, K., Komatsu, K., Ouchi, Y., Ishii, H., \& Seki, K. (2007). Atmospheric Effect of Air, N2, O2, and Water Vapor on the Ionization Energy of Titanyl Phthalocyanine Thin Film Studied by Photoemission Yield Spectroscopy. $J$. Appl. Phys., 102. doi:10.1063/1.2809360.

8. Monjushiro, H., Watanabe, I., \& Yokoyama, Y. (1991). Ultraviolet Photoelectron Yield Spectra of Thin Gold Films Measured in Air. Anal. Sci., 7, 543-547. doi:10.2116/ analsci.7.543.

9. Grzibovskis, R., \& Vembris, A. (2016). Study of the P3HT/PCBM Interface Using Photoemission Yield Spectroscopy. Org. Photonics, 7, 98950Q. doi:10.1117/ 12.2227823.

10. Grzibovskis, R., \& Vembris, A. (2018). Energy Level Determination in Bulk Heterojunction Systems Using Photoemission Yield Spectroscopy: Case of P3HT:PCBM. J. Mater. Sci., 53, 75067515. doi:10.1007/s10853-018-2050-9.

11. Wang, Y., Chen, J., Do Kim, H., Wang, B., Iriguchi, R., \& Ohkita, H. (2018). Ternary Blend Solar Cells Based on a Conjugated Polymer with Diketopyrrolopyrrole and Carbazole Units. Front. Energy Res., 6, 1-9. doi:10.3389/fenrg.2018.00113. 
12. Hou, J., \& Guo, X. (2013). Active Layer Materials for Organic Solar Cells. Green Energy Technol., 128, 17-42. doi:10.1007/978-1-4471-4823-4_2.

13. Li, J., Liang, Z., Peng, Y., Lv, J., Ma, X., Wang, Y., ... \& Xia, Y. (2018). 36\% Enhanced Efficiency of Ternary Organic Solar Cells By Doping a NT-Based Polymer as an Electron-Cascade Donor. Polymers (Basel), 10. doi:10.3390/polym10070703.

14. Wu, J., Yue, G., Xiao, Y., Lin, J., Huang, M., Lan, Z., ... \& Sato, T. (2013). An Ultraviolet Responsive Hybrid Solar Cell Based on Titania/Poly(3- Hexylthiophene). Sci. Rep., 3. doi:10.1038/srep01283.

15. Safriani, L., Risdiana, R., Fitrilawati, F., Manawan, M., Bahtiar, A., Aprilia, A., ... \& Watanabe, I. (2018). Charge Carrier Transport in Blend of $\mathrm{P} 3 \mathrm{HT}$ and $\mathrm{ZnO}$ Nanoparticles at Low Temperature Studied by usR. J. Phys. Conf. Ser., 1080, 0-5. doi:10.1088/1742-6596/1080/1/012011.

16. Hill, I.G., Kahn, A., Soos, Z.G., \& Pascal, R.A. (2000). Charge-Separation Energy in Films of $\pi$-Conjugated Organic Molecules. Chem. Phys. Lett., 327, 181-188. doi:10.1016/S0009-2614(00)00882-4.

17. Fahlman, A., Hamrin, K., Hedman, J., Nordberg, R., Nordling, C., \& Siegbanh, K. (1966). Electron Spectroscopy and Chemical Binding. Nature, 210, 4-8. doi:https://doi. org/10.1038/210004a0.

18. Grzibovskis, R., Vembris, A., Sebris, A., Kapilinskis, Z., \& Turks, M. (2018). Energy Level Determination of Purine Containing Blue Light Emitting Organic Compounds. Proc. SPIE., 10687, 47. doi:10.1117/12.2307422.

19. Sworakowski, J., Lipiński, J., \& Janus, K. (2016). On the Reliability of Determination of Energies of HOMO and LUMO Levels in Organic Semiconductors from Electrochemical Measurements. A Simple Picture Based on the Electrostatic Model. Org. Electron., 33, 300-310. doi:10.1016/j. orgel.2016.03.031.

20. Sworakowski, J., \& Janus, K. (2017). On the Reliability of Determination of Energies of HOMO Levels in Organic Semiconducting Polymers from Electrochemical
Measurements. Org. Electron., 48, 46-52. doi:10.1016/j.orgel.2017.05.031.

21. Whitcher, T.J., Wong, W.S., Talik, A.N., Woon, K.L., Rusydi, A., Chanlek, N., ... \& Songsiriritthigul, P. (2018). Energy Level Alignment of Blended Organic Semiconductors and Electrodes at the Interface. Curr. Appl. Phys., 18, 982-992. doi:10.1016/j.cap.2018.05.002.

22. Luo, H., Lai, J., Wang, C., \& Chen, Q. (2018). Understanding the Effects of the Energy Band Alignment at the Donor/Acceptor Interface on the Open Circuit Voltage of Organic Photovoltaic Devices. Chem. Phys. Lett., 711, 113-117. doi:10.1016/j. cplett.2018.08.074.

23. Kim, H.B., \& Kim, J.J. (2018). A Simple Method to Measure Intermolecular ChargeTransfer Absorption of Organic Films. Org. Electron., 62, 511-515. doi:10.1016/j. orgel.2018.06.022.

24. List, M., Sarkar, T., Perkhun, P., Ackermann, J., Luo, C., \& Würfel, U. (2018). Correct Determination of Charge Transfer State Energy from Luminescence Spectra in Organic Solar Cells. Nat. Commun., 9, 1-8. doi:10.1038/s41467-018-05987-8.

25. Khan, S.U.Z., Londi, G., Liu, X., Fusella, M.A., D'Avino, G., Muccioli, L., ... \& Rand, B.P. (2019). Multiple Charge Transfer States in Donor-Acceptor Heterojunctions with Large Frontier Orbital Energy Offsets. Chem. Mater., 31, 6808-6817. doi:10.1021/ acs.chemmater.9b01279.

26. Ruduss, A., Traskovskis, K., Grzibovskis, R., \& Kokars, V. (2019). Synthesis and Photoelectrical Properties of 3-(Diphenylamino)Carbazolyl

Functionalized DMABI Derivatives. Key Eng. Mater, 280-285. doi:10.4028/www. scientific.net/KEM.800.280.

27. Ruduss, A., Traskovskis, K., Vembris, A., Grzibovskis, R., Pudzs, K., Lielbardis, M., \& Kokar, V. (2019). Synthesis and Investigation of Charge Transport Properties in Adducts of Hole Transporting Carbazole Derivatives and Push-Pull Azobenzenes. J. Phys. Chem. Solids., 127, 178-185. doi:10.1016/j. jpcs.2018.12.019. 